\title{
EMERGENCY RESPONSES TO THE COVID-19 CRISIS IN EDUCATION: A SHIFT FROM CHAOS TO COMPLEXITY
}

\author{
Barbi Svetec, Blaženka Divjak, Faculty of Organization and Informatics, University of \\ Zagreb, Croatia
}

\section{Abstract}

This paper presents a pilot research of approaches taken by European Union (EU) Member States (MSs) in the emergency response to the COVID-19 crisis in pre-tertiary education. It includes a multi-case study of four MSs, examining their education systems' digital readiness and "fitness for change", as well as decision-making practices. We use the Cynefin framework of decision contexts to explore different paths in shifting from chaos to complexity. The preliminary findings of this research indicate that a factor positively influencing education systems' response was not exclusively their digital readiness, but also "fitness" in terms of ongoing reforms and preparedness for change. The findings also suggest that MSs generally continued with their usual decision-making practices, with tendencies towards centralisation of crucial decisions, which is in line with the Cynefin framework, arguing for stronger leadership in chaotic contexts.

\section{Introduction}

Due to the COVID-19 pandemic, across the EU, from mid-March 2020 and for at least two months, school closures were nearly universal, affecting more than 95 million students at all educational levels (EC, 2020g; p.11). In the worldwide emergency, education leaders had to "adopt a proactive approach to contributing to the mitigation of the impact of the pandemic and to prevent learning loss" (Reimers \& Schleicher, 2020; p.7). The shift to distance learning relied heavily on digital learning practices, though the switch to digital learning and teaching often had to be done with haste and without enough time for preparation (EC, 2020e; p.6). However, "emergency is not the time to put into effect complex institutional plans for distance learning that were meant to be implemented over months or years" (Daniel, 2020; p.93). Despite the substantial development of digital infrastructure of schools in the past decade, there are still significant disparities between MSs (EC, 2020g, p. 11), and while digital technologies enabled numerous students to continue learning in the crisis, there was also a barrier for those lacking access, equipment 
Svetec, B., \& Divjak, $B$.

Emergency Responses to the COVID-19 Crisis in Education: A Shift from Chaos to Complexity

or skills (EC, 2020e; p.3). Even though all MSs resorted to predominantly digital learning and teaching, there were differences in their approaches. Some may be linked with the digital readiness of their education systems, others with national specificities and traditions, including those related to decision-making.

\section{Theoretical foundation of research}

To make a better understanding of the decision-making in the context of the COVID-19 crisis in pre-tertiary education, it may be useful to put it in the perspective of the Cynefin framework, as created by David Snowden. In Snowden's words (2002; p.104), “Cynefin creates four open spaces or domains of knowledge all of which have validity within different contexts". As pointed out by French (2015; p.1638), the Cynefin framework was introduced "to categorise contexts for inference and learning, knowledge management and decision making”. Snowden and Boone (2007; p.2) emphasised that, in the Cynefin framework, contexts are "defined by the nature of the relationship between cause and effect". In the four contexts, simple, complicated, complex, and chaotic, leaders need to recognise the situation and act appropriately. Simple contexts include stability and clear relationships between cause and effect, apparent and uncontested answers, unquestioned decisions, and common understanding. Complicated contexts also contain clear relationships between cause and effect, but these are not evident to everyone; they can include several right answers and require looking into various options, which may call for expertise. In complex contexts, the right answer cannot be identified, and reasons behind events can be understood only in hindsight; in such contexts, leaders need to let patterns and possible solutions emerge and then identify the appropriate ones. In chaotic contexts, it is not possible to identify the relationships between cause and effect, as they are changing, and there are no patterns to identify; leaders need to act immediately to set up order, detect where there is stability, and then work to shift from chaos to complexity, where patterns can be identified, which may contribute to preventing further crises and recognising opportunities (Snowden \& Boone, 2007). According to Kurtz and Snowden (2003; p.477), shifting from the chaotic to the complex is "a matter of creating multiple attractors, or swarming points, around which un-order can instantiate itself". McLeod and Childs (2013) pointed to a similar way of discussing management styles, in relation to tame and wicked problems, as distinguished by Rittel and Webber (1973). Namely, according to Grint (2005; p.1473), tame problems are complicated and wicked are complex, the third type, he identified as critical, was associated by McLeod and Childs with the chaotic domain (2013; p.123). From the perspective of behavioural strategy, Foss (2020; p.1324) stressed that decision-making in the COVID-19 emergency had been characterised by "novelty, complexity and open-endedness" (with reference to Mintzberg et al., 1976) and a "lack of clarity". 


\section{Emergency Responses to the COVID-19 Crisis in Education: A Shift from Chaos to Complexity}

If put in the perspective of Cynefin, the onset of the pandemic in March 2020 has all characteristics to be identified as a chaotic context. It brought a severe emergency and concern about human safety, calling for an instant response and immediate decisionmaking, taking into account the constantly changing, completely unpredictable circumstances. Probing actions and decisions made in this context were the basis for a further shift to a complex context, with some patterns and solutions already emerging, some stability returned, and new opportunities revealed. In the complex context, some sort of an organised educational process has started, i.e. a majority of students have instruction on a regular daily basis and teachers have support in the delivery of teaching. Nevertheless, there are still many unknowns and incomplete solutions, such as those related to vulnerable groups of students and teachers left behind, as well as the social component of learning and good assessment practices missing on a broader level. In the next section, we are going to analyse the approaches taken by MSs in the first semester of 2020 to make the shift from chaos to complexity, using Cynefin as a theoretical framework.

\section{Methodology}

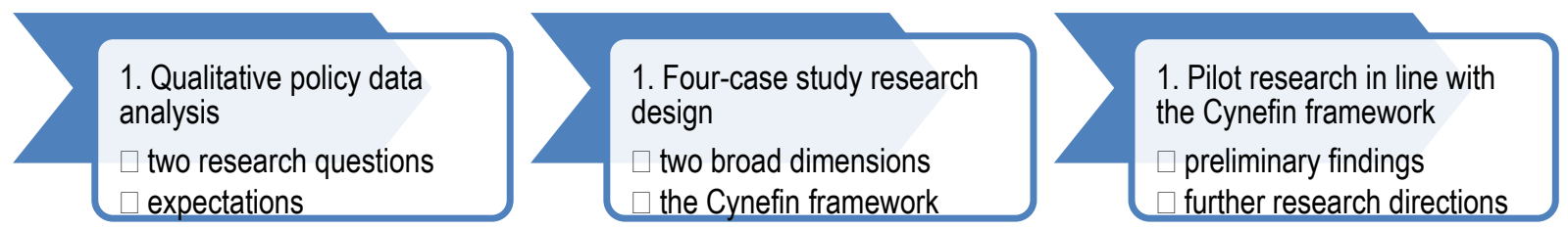

Figure 1. Research design of the pilot research

As presented in Figure 1, the first step in our research was a qualitative data analysis, which included primarily policy papers, national and official EU documents, as well as international organisations' research reports, related to the development of digital education and responses of MSs' education systems to the pandemic. Based on that, we recognised there had been significant differences between MSs' education systems before the pandemic, related to several factors. As the most prominent ones, we identified the state of reform processes in education and the level of digitalisation. Besides that, we recognised that the responses to the pandemic's threat to education included centralised support, digital repositories and training, but also decentralised, often school-level, organisation and responsibility for the continuation of educational processes.

In the second step, we used the multi-case study research method and placed MSs in a matrix based on two categories (Yin, 2018). The first category referred to the digital readiness of an MS's education system and its "fitness" for the emergency shift to predominantly digital learning and teaching. The European Framework for Digitally Competent Educational Organisations was consulted, which proposes seven key elements related to effective digital education: teaching and learning practices, professional development, assessment practices, content and curricula, collaboration and networking, 
infrastructure, and leadership and governance practices (EC, 2015). Based on that, we examined to what extent education systems had been modernised, in terms of e.g. availability of equipment, teachers' and students' digital skills, and curricula. The second category referred to the level of centralised versus decentralised decision-making in education. Here we examined e.g. at what levels crucial decisions were made and whether support and guidance were provided by education authorities. Based on the combination of the two categories, we grouped MSs into four clusters, as shown in Figure 2.

In the third step, we conducted a pilot research. We selected one distinguished representative from each of the clusters and researched its case in more detail, to demonstrate different national circumstances and approaches. Since, in the case study research design, sufficient access to data is needed and it is suggested that cases which are most likely to provide answers to research questions should be chosen (Yin, 2018), cluster representatives with the most adequate public data were selected. The aim of the pilot research was to answer two research questions.

- RQ1: What approaches did MSs take in their immediate response to the COVID-19 crisis, considering their digital readiness? Our expectation was that successful shifting did not depend exclusively on high digital readiness.

- RQ2: Was the level of decision-making during the COVID-19 crisis aligned with the regular orientation of an MS's education system in terms of (de)centralisation? Our expectation was that MSs stayed aligned with the regular level of (de)centralisation of decision-making and guidance.

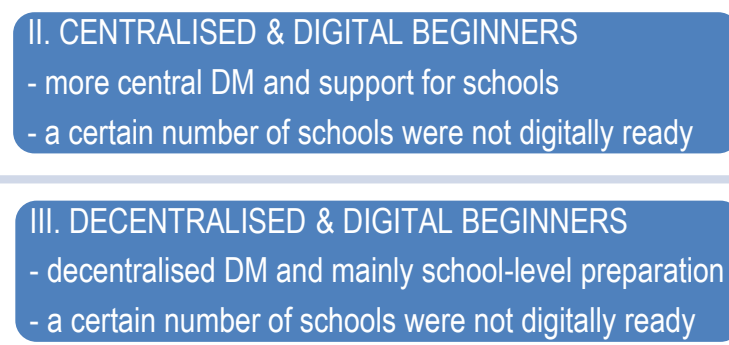

I. CENTRALISED \& A DIGITAL "MOVER"
- central decision-making (DM) and support for schools
- a majority of schools were digitally ready
IV. DECENTRALISED \& DIGITALLY MATURED
- decentralised DM and school-level preparation
- a majority of schools were digitally ready

Figure 2. Clustering of MSs according to two categories

\section{Results}

\section{Croatia as a representative of cluster $I$.}

According to the Digital Economy and Society Index (DESI) 2020 (based on 2019 data), though positioned slightly below the EU average on the percentage of individuals with at least basic digital skills, Croatia was slightly above the EU average in above-basic digital skills (EC, 2020a; p.7). Croatia is the only MS with all 16-19 year-olds having at least basic digital skills. A Comprehensive Curricular Reform and the e-Schools project have been in 
Svetec, B., \& Divjak, B.

Emergency Responses to the COVID-19 Crisis in Education: A Shift from Chaos to Complexity

full roll-out since 2019, enhancing the use of ICT in learning and teaching. Since 2018/2019, Informatics has been a compulsory subject in certain grades of primary and secondary schools and optional in others, and since 2019/2020 ICT included as a crosscurricular topic in all grades. (EC, 2020f; p.44) The Teaching and Learning International Survey (TALIS) 2018 showed that a below-average percentage of teachers felt (very) well prepared to use ICT in teaching and let students frequently/always use ICT for schoolwork. However, an above-average percentage had ICT for teaching included in recent professional development activities. (OECD, 2019; p.30) In 2019, more than 40000 teachers underwent training within the curricular reform and the e-Schools project (EC, 2020f; p.44). Considering the infrastructure, although in 2017-2018 schools were less equipped and connected than the EU average (EC, 2019a; pp.39-40), since 2019, two large projects (e-Schools and Comprehensive Curricular Reform) have been providing all schools with the necessary equipment, and within the curricular reform, students have been provided with tablets. Croatia managed to respond well to the crisis, with current reforms and projects providing the basis for a rapid shift to distance education and effective provision of online classes (EC, 2020f; p.45). Considering decision-making, education governance is divided between the state level and municipalities. Decisions on closure and re-opening of schools were made at the central level, and national education authorities provided strong guidance and support (MSE, 2020b). As the crisis started, video lessons were provided centrally for both primary and secondary schools, available via television and online (EC, 2020f; p.49). Teachers were encouraged to prepare and deliver their own content and set up virtual classrooms. Various targeted documents were issued to support the transition, including instructions on the organisation of distance learning and teaching, and assessment and grading in virtual environments. (MSE, 2020b) An Action Plan for the Development of Distance Education was developed (MSE, 2020a).

\section{Hungary as a representative of cluster II.}

The DESI index 2020 suggested that in Hungary, the proportion of individuals with both at least basic and above-basic digital skills was below the EU average, with no progress made in recent years (EC, 2020c; p.7). An outline of the digital competence framework was adopted in 2019. A new core curriculum, introducing the subject "digital culture", was published to apply from September 2020 (EC, 2020f; p.154). TALIS 2018 suggested that an above-average percentage of teachers felt (very) well prepared to use ICT in teaching, but a below-average percentage let students frequently/always use ICT for school work (OECD, 2019; p.30). In 2017-2018, schools were far less digitally equipped and connected than the EU average (EC, 2019a; pp.39-40). Project funding in 2017-2020 provided equipment for state schools in less developed regions, and equipment and training for teachers (EC, 2020f; p.158). The transition to predominantly digital learning and teaching during the crisis pointed to differences in teachers' preparedness and students' access. 
Yearly national competence testing suggested that about $20 \%$ of students had limited or no access to digital education (Hermann, 2020, as cited in EC, 2020f), which might have worsened the learning deficit of disadvantaged students. (EC, 2020f; p.154) Education governance is shared between the central government and municipal school districts, and recent reforms have centralised the system (OECD, 2015a; p.15). Decisions regarding closure and re-opening of schools and adaptation of teaching practices were orchestrated at a more central level (OECD, 2021; p.47). The education authority issued a recommendation for the organisation of digital education, and distance education was supported by a central platform, though other collaborative spaces were used as well (EC, 2020c; p.4) and each school could select a digital platform to work with (Molnar et al., 2020; p.606).

\section{Slovakia as a representative of cluster III.}

As reported in the DESI index 2020, the percentage of individuals with both at least basic and above-basic digital skills was below the EU average, with a decrease in numbers (EC, 2020d; p.7). Schools are autonomous to decide whether to include digital competences as a separate subject or integrated in other compulsory subjects (EC, 2019b; p.30). According to TALIS 2018, an around-average percentage of teachers felt (very) well prepared to use ICT in teaching, but a below-average percentage let students frequently/always use ICT for school work (OECD, 2019; p.30). In 2018 it was established that in lower secondary schools teachers used ICT mostly to present content, and rarely to enhance students' knowledge (State School Inspectorate, 2018, as referenced in EC, 2020f; p.280). In 2017-2018, schools were less digitally equipped and connected than the EU average (EC, 2019a; pp.39-40). Though digitally equipping schools and students has been a priority, the crisis highlighted the lack of adequate digital resources, the need for equal access to quality digital learning, as well as improving teachers' digital skills, learning management systems, and support to the disadvantaged (EC, 2020f). Decision-making usually involves the state, municipality/region, and school level, with schools granted relatively high autonomy (OECD, 2015b; p.15). While decisions on closure or re-opening of schools were made at the central level, schools had autonomy in deciding on learning resources, teaching requirements, and adapting teaching practices (OECD, 2021; p.47). Education authorities established a portal to support online learning and teaching and assessment (EC, 2020d; 2020f).

\section{Finland as a representative of cluster IV.}

According to the DESI index 2020, Finland ranked among the highest in the EU in both at least basic and above-basic digital skills (EC, 2020b; p.7). Digital competences are included in curricula; since 2016-2017 in primary and lower secondary education transversally, and in upper secondary education there are related optional courses. Digital skills of teachers 


\section{Emergency Responses to the COVID-19 Crisis in Education: A Shift from Chaos to Complexity}

are highly developed. (EC, 2020f, p. 103) According to TALIS 2018, a below-average percentage of teachers felt (very) well prepared to use ICT for teaching, but an aroundaverage percentage frequently/always let students use ICT for school work (OECD, 2019; p.30). In 2017-2018, Finland was among the highest-ranking MSs in terms of digitally equipped and connected schools (EC, 2019a; pp.39-40). Well-developed digital education, with high-skilled teachers and good infrastructure, enabled successful dealing with the crisis. Though distance education worked well, there is also a fear that students in need of more support might have progressed less than their peers. (EC, 2020f) Finland's education system is highly decentralised, with most education-related decisions taken at a municipal and institutional level (OECD, 2020; p.18). Decisions on closure and re-opening of schools were made at the central level, on learning resources and teaching requirements at a local level, and on adapting teaching practices at multiple instances (OECD, 2021; p.47). Support and guidance were provided at the central level. Several main education platforms were used; there was an online hub with resources created to support teachers. (EC, 2020f; p.107) The fact that decisions regarding technical and practical aspects were left to municipalities and schools is "one example of the high level of trust in teachers and school leaders that defines much of what happens in Finnish schools" (Sahlberg, 2020; p.363).

\section{Discussion}

It could be argued that the onset of the pandemic in March 2020 had all elements to be characterised as a chaotic context. As pointed out by Foss, the situation was "deeply uncertain and ambiguous" and "sensemaking" was particularly important (2020; p.1324). Several months, or even weeks into the pandemic, when certain practices were established, a great majority of MSs were already in a complex context, able to analyse the situation, draw lessons and make more structured plans. They had different starting positions, national contexts, and traditions, both of which might have affected their approaches. We tried to shed light on these aspects to enable a better understanding of their responses.

If we look at the digital readiness, based on the limited number of cases, it could be argued that education systems that were better prepared in terms of digital skills, curricula, and infrastructure, also faced fewer challenges and negative effects in shifting to predominantly digital learning and teaching. On the one hand, there is Finland which, according to the DESI index 2020 (EC; 2020b), was placed the highest in the overall ranking, as well as in the human capital category, with digital skills well above the EU average. Finland has digital competences included in the curricula, highly skilled teachers, and adequate infrastructure. It does not surprise that, with such preconditions, Finland was able to successfully manage the crisis. On the other hand, there is Croatia, ranking below the EU average in the overall DESI 2020 index (EC; 2020a), and a bit below the average in the human capital category, but above-average in advanced digital skills. In 


\section{Emergency Responses to the COVID-19 Crisis in Education: A Shift from Chaos to Complexity}

Croatia, digital competences have only recently been included in the curricula, and teachers' competences and infrastructure have advanced rapidly in the last several years. Croatia also managed to respond well to the crisis, which was largely enabled by recent projects and initiatives focused on the development of digital education, underway as the crisis struck. In this context, it can be noted that education systems "fit for change" were not necessarily and only those ranking the highest on various parameters related to digital capacity. What is also important is the "agility" of the system, its adaptiveness to change, reforms underway, and capacity to react in case of need. Moreover, based on the findings of the four cases, it could be concluded that, in cases of MSs which were less digitally prepared and possibly less "fit for change", this shift to large-scale digital education highlighted the existing gaps, primarily in infrastructure and access, as well as teachers' competences. Though learning inequalities are not linked only with MSs whose systems were less digitally ready, their scale may depend on the digital readiness. Finally, regarding our research questions, we could say that the pilot research supports our expectation that a successful response to the crisis was not predetermined by a high level of digital readiness. To answer the research question with higher confidence, more case studies should be considered.

As far as decision-making is concerned, it was connected to different levels of governance in different MSs. Although Snowden and Boone argue that, in chaotic contexts, "communication of the most direct top-down or broadcast kind is imperative" (2007; p.6), this should be put in the perspective of already established practices, not to worsen the chaos by introducing new ones amidst of it. If we look at the four analysed MSs, it can be concluded that decisions regarding the closure and re-opening of schools were made at more centralised levels - even in Finland, with its decentralised education system, which may be interpreted in support of the mentioned claim by Snowden and Boone. However, when it comes to decisions related to adapting teaching practices, the findings show different practices, including both centralised and decentralised decision-making. Across the EU (EC; 2020f), guidance and support were in some form (guidelines, platforms, repositories or other) provided at the centralised level. Considering the limitations of the available data, it is not really possible to draw conclusions about how strong, overarching or used these support and guidance were, though. However, regardless of that, it can be concluded that schools also had high levels of responsibility - in MSs such as Slovakia or Finland, they were supported but had broad autonomy, and in Croatia, they were firmly guided but the final implementation was also down to them. Nevertheless, if we return to our research question, we can conclude that the locus of decision-making during the crisis did reflect the regular organisation of education governance, but also that in some MSs the role of central-level decision-making might have been stronger than in regular contexts. 
The last could be expected if we consider the Cynefin framework, where it is noted that, in a chaotic context, stronger leadership is needed to move to a less ambiguous situation.

We propose some preliminary findings, but with a wide range of limitations arising from the limited number of cases and methodological constraints. It can be argued that there was no universal approach in transitioning from chaos to complexity and that successful responses were achieved using different approaches. However, there are numerous other aspects (variables) in MSs' responses to the crisis, which could also be distinguished as important. For example, the quality of learning and teaching, acquired learning outcomes, and inclusiveness would be essential dimensions in determining the success of a response for all students at a satisfactory level. These aspects would be worth exploring in further research. Moreover, this paper focuses primarily on the initial responses in early 2020 (though some data refer to the entire year), so in further research, longitudinal data collection needs to be conducted. It would be worth exploring how MSs have been dealing later on, in complex contexts, and establish whether possibly, as patterns have emerged and the pandemic is being put under control, these may already be characterised as complicated. Finally, lessons learned from this crisis must be carefully noted and collected, to build education systems' resilience to similar threats in the future.

\section{Conclusions}

In this paper, we presented a pilot research focused on the emergency responses of EU MSs' education systems in the first months of the COVID-19 crisis. The research included a multi-case study of four MSs, in which their digital readiness before the crisis and "fitness for change", as well as the orchestration of decision-making in the crisis were examined. The decision-making process that enabled the shift from chaos to complexity was discussed from the perspective of the Cynefin framework. The results of the multi-case study suggest that high digital readiness before the crisis may not have been the necessary prerequisite for a successful shift to mostly digital learning and teaching and that even though MSs were inclined to keep their usual decision-making practices, there were tendencies towards more centralised country-level approaches, which is in line with the Cynefin framework, suggesting stronger leadership is needed in chaotic contexts. However, considering the limitations of this research and numerous other aspects which may be relevant when discussing education systems' responses, its role is primarily to open questions and call for further research, and not to elicit any final conclusions. 


\section{References}

Daniel, S. J. (2020). Education and the COVID-19 pandemic. Prospects, 49(1-2), 91-96.

European Commission. (2019a). 2nd survey of schools: ICT in education: objective 1: benchmark progress in ICT in schools, final report.

European Commission. (2019b). Digital education at school in Europe [Eurydice Report].

European Commission. (2020a). Digital economy and society index (DESI) 2020, country profile-Croatia.

European Commission. (2020b). Digital economy and society index (DESI) 2020, country profile-Finland.

European Commission. (2020c). Digital economy and society index (DESI) 2020, country profile-Hungary.

European Commission. (2020d). Digital economy and society index (DESI) 2020, country profile-Slovakia.

European Commission. (2020e). Digital education action plan 2021-2027: Resetting education and training for the digital age.

European Commission. (2020f). Education and training monitor 2020: Country analysis.

European Commission. (2020g). Education and training monitor 2020: Teaching and learning in a digital age.

European Commission. Joint Research Centre. (2015). Promoting effective digital-age learning: A European framework for digitally competent educational organisations.

Foss, N. J. (2020). Behavioral Strategy and the COVID-19 Disruption. Journal of Management, 46(8), 1322-1329.

French, S. (2015). Cynefin: Uncertainty, small worlds and scenarios. Journal of the Operational Research Society, 66(10), 1635-1645.

Grint, K. (2005). Problems, problems, problems: The social construction of 'leadership'. Human Relations, 58(11), 1467-1494.

Kurtz, C. F., \& Snowden, D. J. (2003). The new dynamics of strategy: Sense-making in a complex and complicated world. IBM Systems Journal, 42(3), 462-483.

McLeod, J., \& Childs, S. (2013). A strategic approach to making sense of the "wicked" problem of ERM. Records Management Journal, 23(2), 104-135. 
Ministry of Science and Education. (2020a). Action Plan for Development of Distance Education - Distance Education Model. Retrieved from https://mzo.gov.hr/news/coronavirus-organisation-of-distance-teaching-andlearning-in-croatia/3634

Ministry of Science and Education. (2020b). Coronavirus - organisation. Retrieved 7 May, 2021, from https://mzo.gov.hr/news/coronavirus-organisation-of-distance-teachingand-learning-in-croatia/3634

Molnar, G., Namesztovszki, Z., Glusac, D., Karuovic, D., \& Major, L. (2020). Solutions, experiences in online education in Hungary and Serbia related to the situation caused by Covid-19. Proceedings of the $202011^{\text {th }}$ IEEE CogInfoCom, 601-606.

OECD. (2015a). Education Policy Outlook: Hungary. Retrieved from https://www.oecd.org/education/policyoutlook.htm

OECD. (2015b). Education Policy Outlook: Slovak Republic. Retrieved from https://www.oecd.org/education/policyoutlook.htm

OECD. (2019). TALIS 2018 Results (Volume I) Teachers and School Leaders as Lifelong Learners. OECD Publishing.

OECD. (2020). Education Policy Outlook: Finland. Retrieved from https://www.oecd.org/education/policyoutlook.htm

OECD. (2021). The state of school education: One year into the COVID pandemic.

Reimers, F. M., \& Schleicher, A. (2020). A framework to guide an education response to the COVID-19 pandemic of 2020 [OECD Policy Responses to Coronavirus (COVID-19)]. OECD.

Rittel, H. W. J., \& Webber, M. M. (1973). Dilemmas in a general theory of planning. Policy Sciences, 4(2), 155-169.

Sahlberg, P. (2020). Will the pandemic change schools? Journal of Professional Capital and Community, 5(3/4), 359-365.

Snowden, D. (2002). Complex acts of knowing: Paradox and descriptive self-awareness. Journal of Knowledge Management, 6(2), 100-111.

Snowden, D. J., \& Boone, M. E. (2007). A Leader's Framework for Decision Making. Harvard Business Review, 10.

Yin, R. K. (2018). Case study research and applications: Design and methods (6 $6^{\text {th }}$ ed.). Los Angeles: SAGE. 